Article

\title{
Experimental Investigation on the Effect of Shot Peening and Deep Rolling on the Fatigue Response of High Strength Fasteners
}

\author{
Barbara Reggiani ${ }^{1, *(1)}$ and Giorgio Olmi ${ }^{2}$ (I) \\ 1 DISMI Department of Sciences and Methods for Engineering, University of Modena and Reggio Emilia, \\ Reggio Emilia, 42122 Modena, Italy \\ 2 DIN Department of Industrial Engineering, University of Bologna, 40136 Bologna, Italy; \\ giorgio.olmi@unibo.it \\ * Correspondence: barbara.reggiani@unimore.it; Tel.: +39-0522-522-652
}

Received: 5 September 2019; Accepted: 9 October 2019; Published: 11 October 2019

\begin{abstract}
Shot-peening and deep rolling are mechanical surface treatments that are commonly applied to enhance the fatigue performances of components, owing to their capacity to generate compressive residual stresses and induce work hardening. However, literature is still poor of published data concerning the application of these treatments to high strength steels fasteners, although these represent a class of components among the most widespread. In the present work, the impact of deep rolling and shot-peening performed in the underhead radius of two set of fasteners made of $36 \mathrm{NiCrMo}$ and $42 \mathrm{CrMoV}$ for fatigue life enhancement has been investigated. The experimental tests consisted of six combinations of shot-peening and deep rolling, including the non-treated state. Two test campaigns have been sequentially carried out with different process parameters and treatment sequences. The results always showed a beneficial impact of the deep rolling on fatigue, especially for the $42 \mathrm{CrMoV}$ steel. Conversely, the effect of the shot-peening strongly depended on the selected set of parameters, alternatively leading to an improvement or a worsening of the fatigue life in relation to the level of induced surface roughness.
\end{abstract}

Keywords: deep rolling; shot-peening; fatigue life; fasteners; high-strength steels

\section{Introduction}

Surface treatments are frequently used in many industrial applications to increase the in-service performances of components. Specifically, for highly cyclically loaded parts, mechanical treatments, such as shot-peening and deep rolling, are commonly applied with the aim to enhance the fatigue life and strength, leading to different properties of the surface layer with respect to those of the bulk material [1-3].

Shot-peening consists in hitting the surface at high speed with micro balls being hardener than the treated material and acting as local hammers, thus producing a force that is able to induce a plastic deformation in a thin layer of material. On the other hand, deep rolling makes use of a series of rolling elements to plastically deform the surface layer by generating a compressive force that is applied up to a certain value with a selected time law [3]. The many works that were reported in literature proved that the basic mechanisms that support the fatigue life increment of mechanically treated surfaces are mainly related to the induced near-surface compressive residual stresses $[4,5]$. These have the twofold benefit of reducing the load acting on the component and largely suppressing the crack propagation from the surface towards the bulk. A further positive effect is associated to the intense induced work hardening resulting in high dislocation densities that strengthened near-surface 
regions, thus allowing for retarding fatigue crack nucleation [2,4]. Moreover, in the case of deep rolled components, the enhancement can derive from the elimination, or at least the reduction, of micro notches, thus leaving a smoother surface with the related well known beneficial impact on the fatigue life [2]. Depending on the material of the treated surface, other property modifications can result from stress-induced martensitic transformations and/or transformations in near-surface crystallographic textures [4].

Among the several rotation-symmetrical components that can take advantage of the deep rolling treatment, high loaded fasteners are typical examples, since, owing to the nature of their application, they frequently operate under cyclic loads, thus making fatigue the most frequent failure mode [6]. Despite this aspect, not so many works in literature systematically explore the design issues of fasteners with the aim of addressing their resistance against fatigue failure [7]. As a general rule, engineers often select fasteners based on their specifications for strength (tensile or yield strength) without specifically considering fatigue. In addition, the time and cost consuming activities that are required for these optimization tasks, and the sensitivity of the generated data, force many companies to regard them as confidential without sharing the results of their research. Finally, fastener suppliers not always can span a completely design freedom, as they are subjected to strict constraints that are imposed by customers that prescribe strict geometrical specifications. All of these design limitations thus pushed towards the solution that is offered by surface treatments to improve the fatigue resistance.

As previously stated, several works have already been published in the literature on the effect of shot-peening and deep rolling on various materials, but they mainly deal with standard cylindrical notched/unnotched specimens [8-13] or with crankshafts [14-17]. Conversely, only few works have been done that specifically focused on the effect of surface treatments in fasteners. Li et al. [18] investigated the residual stresses that are induced by rolling of an underhead $R=0.64 \mathrm{~mm}$ fillet with regard to bolts made of a nickel based superalloy and compared the effectiveness of different experimental techniques. As a result, fillet rolling induced compressive residual stresses in a $0.5 \mathrm{~mm}$ deep surface layer, up to a maximum of $1600 \mathrm{MPa}$.

Within the variety of materials for fasteners, the technologies and practises that are applied in attaining weight reduction in transportation sectors proved that steel remains the most economical and sustainable material for vehicle manufacturing and the principle of steel-based light weighting is to replace mild steels by high strength steels, thus reducing the material thickness [19]. In this context, now even more restricted to steels, only a single work has been found that was performed by Kloos et al. [20], which explored how the operating parameters of the deep rolling were able to affect the fatigue strength of specimens made of $42 \mathrm{CrMo} 4$ and marked by an underhead fillet radius of $1.35 \mathrm{~mm}$. As the main outcome, the deep rolling process removed the notch effect, contributing to a fatigue life increase of $190 \%$ with respect to the notched and untreated condition.

No previous work dealt with the specific application of shot-peening at the underhead fillet of fasteners for the enhancement of the fatigue life, to the best of the authors' knowledge. On the other hand, recent studies [21,22] have highlighted its beneficial impact on the tribological response, through friction coefficient as well as wear drop down. A friction coefficient reduction, as well as its steady trend, even under repeated tightenings, is usually a highly desirable response for screws, as it makes possible to ensure the achievement of the required preload upon tightening under torque control. In fact, the dimples that are created by shot impacts have the capability of incrementing the number of contacts of mating surfaces, acting as pockets that can collect wear debris and retain the lubricant, thus generating hydrostatic pressures that enhance their features.

In this framework, the aim of the present work was the experimental investigation on the effect of the shot-peening and deep rolling surface treatments on the fatigue response of high strength steel fasteners under in-service cyclic tensile stresses. 


\section{Tested Materials and Experimental Methods}

Connecting rod screws with a reduced shank that is made of two high strength steels has been investigated in the present study, while considering the most frequent failure mode under fatigue with fracture occurring in the region of the underhead fillet radius (with $0.35 \mathrm{~mm}$ radius). A two-factor (shot-peening and deep rolling) design has been set-up and two experimental campaigns with different process parameters have been performed, the second one being arranged following the results that were yielded by a former set of tests, already partially reported in [23] and here included for completeness of the work.

Limited by the geometry of the underhead, the residual stress measurement was not feasible with the use of conventional techniques, such as hole-drilling or laboratory X-ray diffraction (XRD). The effect of the surface treatments was then evaluated by means of fatigue tests under tension-tension load in order to determine the S-N curves and the fatigue limits (always reported in terms of stress amplitude).

\section{Initial Campaign}

Two different set of reduced shank connecting rod screws were investigated in the present work. The first set of screws was made of $36 \mathrm{NiCrMo}$ and it had an MJ9 X $14 \mathrm{~g}$ grade 13.9 thread with $7 \mathrm{~mm}$ diameter at the reduced shank (Figure 1a) The screw underwent the following heat and forming treatments: cold forging, quenching/tempering, turning, grinding, and thread rolling, achieving a final Rockwell hardness of 44 HRC (detailed information on the technological parameters are not reported for confidentiality reasons). The material was experimentally characterized under static loads and it proved to fulfil the specifications, i.e. a tensile strength between $1300 \mathrm{MPa}$ and $1350 \mathrm{MPa}$, a yield strength of $1100 \mathrm{MPa}$ and $9 \%$ as minimum percentage elongation at fracture. The second set of screws was made of $42 \mathrm{CrMoV}$. The thread was manufactured with $10 \mathrm{~mm}$ as nominal maximum diameter (MJ10 X 14 g grade 14.9) (Figure 1b); moreover, the screw had $8 \mathrm{~mm}$ diameter at the reduced shank. Upon manufacturing, these screws underwent similar treatments (except that they were not ground) to achieve an hardness up to $47 \mathrm{HRC}$ and the static specifications consisted in a tensile strength between $1400 \mathrm{MPa}$ and $1450 \mathrm{MPa}$, a yield strength of $1250 \mathrm{MPa}$, and a minimum elongation at fracture of $11 \%$, which were also verified by experimental characterization.
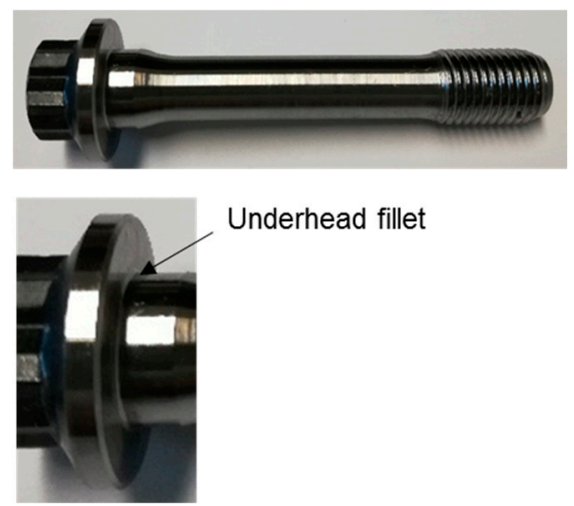

(a)36 NiCrMo
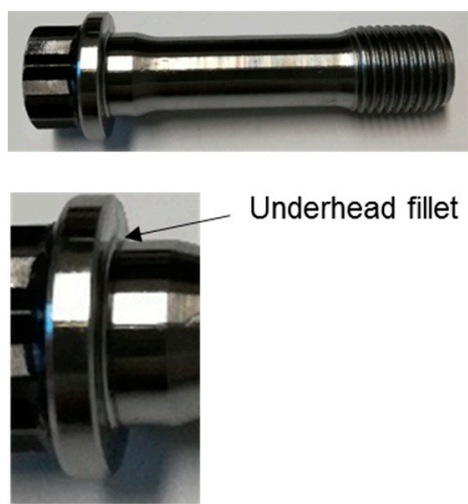

(b) $42 \mathrm{CrMoV}$

Figure 1. The investigated sets of screws.

The geometry of the fasteners was marked by an underhead fillet radius of $0.35 \mathrm{~mm}$, as imposed by the final customer, and fatigue failure always occurred at this location. Indeed, despite what was reported in the literature regarding the most frequent site of fatigue failure in fasteners, i.e. the first thread $[7,24]$, it was experimentally observed by the manufacturer that a sub-head connecting radius of less than $1 \mathrm{~mm}$ causes a fatigue failure that occurred at the fillet.

The experimental trials have been arranged in Table 1, which can be regarded as a two-factor design. In particular, deep rolling has been handled as a two-level factor, when considering the absence 
of this treatment (referenced as level "N" in Table 1) and its execution at the optimized load level (determined in preliminary experimental tests, as detailed in the following) (level " $\mathrm{L}$ ").

Table 1. Two-factor experimental design (first campaign).

\begin{tabular}{cccc}
\hline \multirow{2}{*}{ Deep Rolling } & \multicolumn{3}{c}{ Shot-Peening } \\
\cline { 2 - 4 } & Not Performed & Z100 10-12N & UFS70 10-12N \\
\hline Not Performed & NN & NZ & NU \\
Performed at the & LN & LZ & LU \\
Optimized Load & & & \\
\hline
\end{tabular}

Regarding shot-peening, three levels have been considered: not performed treatment (to be regarded as level " $\mathrm{N}$ " in Table 1), shot-peening by $100 \mu \mathrm{m}$ diameter of ceramic shots (Z100) with 10-12N Almen Intensity and 200\% coverage (level "Z"), shot-peening by $70 \mu \mathrm{m}$ diameter of steel shots (UFS70) with 10-12N Almen Intensity and 200\% coverage (level "U"). Each treatment combination in Table 1 is consequently identified by a combination of two letters, the first one being related to deep rolling and the second one dealing with the subsequent peening treatment. These letters are able to synthetically and univocally indicate the performed treatments, while also taking their order into account.

When both deep rolling and shot-peening have been run (referenced as "LZ" and "LU" in Table 1, shot-peening has been carried out (after deep rolling) at the underhead, the fillet and the not threaded reduced shank. A combination "NN" (neither shot-peening nor deep rolling being performed) corresponded to the as-turned $(42 \mathrm{CrMoV})$ or as-ground $(36 \mathrm{NiCrMo})$ screws and it was regarded as a reference value for comparison purposes.

It must be pointed out that the selected parameters for the shot-peening treatment were initially more specifically conceived to optimize the tribological response of the screws upon tightening and subsequent re-tightening rather than fatigue performance. However, the evaluation of the impact of the same set of parameters on the fatigue response was also within the aim of the present work.

The aforementioned two-factor design was replicated twice, one for each of the two screw materials that were involved in the present study.

The output variable was the fatigue limit, while considering a run-out value of $2 \times 10^{6}$ cycles, meaning that, when failure did not occur before, the test was stopped after two million cycles and a not failure outcome was assumed for further processing. When considering steel materials, run-outs in the range between $10^{6}$ and $10^{7}$ cycles are usually presumed, as they correspond to the number of cycles at the fatigue limit [25]. At a first stage, some preliminary fatigue tests were carried out, while considering a run-out corresponding to $10^{7}$ cycles. Based on the outcome that no failures occurred after one million cycles, the aforementioned value for run-out was considered, also accounting for an extra life span. The experimental results were processed according to the recommendations of ISO 12107 [26] and of the Dixon method [27] for the implementation of an abbreviated staircase sequence that aimed at the estimation of the fatigue limit for infinite life, based on the sequence of failure and not failure events. Sequences consisting of eight nominal specimens (at an average) were considered for each treatment combination in Table 1. In agreement with the aforementioned references, stress steps in the order of the $5 \%$ of the fatigue limit and of its standard deviation were considered. The starting point of the sequence was roughly estimated by some exploratory tests in the finite life domain.

The fatigue tests were performed on a resonant machine, operating at a frequency between 100 and $110 \mathrm{~Hz}$, under a tension-tension load with a fixed mean value corresponding to the recommended preload for the considered screw, being around $85 \%$ of the yield strength, also with regard to the service conditions. The amount of the amplitude load was varied at each test, according to the staircase sequence, depending on the outcome of the previous trial. Therefore, the load ratio (minimum over maximum ratio) was around 0.8 for all of the experimental trials. 


\section{Deep Rolling Optimization}

In the deep rolling process, the underhead of the screws was placed in contact with three rolls made of tungsten carbide equally-spaced by $120^{\circ}$ and initially tilted at $45^{\circ}$ with respect to the axis of the screw. The rolls had the same fillet radius of the screw underhead $(0.35 \mathrm{~mm})$, were free to rotate around their axis, and were mounted on an independent support. This was free to bend by some degrees around a pin, in order to span the entire working zone, from the initial contact point in the underhead towards the shrank, thus including the entire fillet. During the oil lubricated operation, the screw was rotated around its longitudinal axis by a spindle (1200 rpm for 5 to $7 \mathrm{~s}$ ), and compressed against the rolls according to a force ramp up to the target load, thus producing a local plastic deformation and a compressive residual stress state. At the end of the ramp, the load was maintained at the target value for a given time, aiming at achieving the desired plastic flow pattern and at furtherly smoothing the fillet zone treated surface.

The deep rolling process is marked by several parameters, such as the level of friction at the workpiece-rolls interface, the roll material and geometry, the number of passes, the spindle velocity, the feed rate, the load, and workpiece-rolls contact time histories. However, the studies that were reported in literature $[28,29]$ indicate that the rolling load can be regarded as the parameter that mostly affects the outcomes yielded by the process. Specifically, an optimal load can be identified by observing that a further increase leads to a fatigue life drop [2].

At the state of the present work, the deep rolling optimization was then performed with regard to the load that was applied by the rollers for the two sets of investigated materials (and screw geometries). The untreated condition (as-turned for $42 \mathrm{CrMoV}$, as-ground for $36 \mathrm{NiCrMo}$ ) was included in the experimental campaign. Four levels of load were evaluated: untreated, L1, L2 (35\% greater than L1), and $\mathrm{L} 3$ (70\% greater than L1) for 36NiCrMo and untreated, V1, V2 (10\% greater than V1), and V3 ( $45 \%$ greater than $\mathrm{V} 1$ ) for $42 \mathrm{CrMoV}, \mathrm{L} 1$, and $\mathrm{V} 1$ representing the rolling loads commonly applied by the fastener manufacturer (load values are omitted for confidential reasons). The results have been determined in terms of fatigue limits and they are shown in Figure 2.

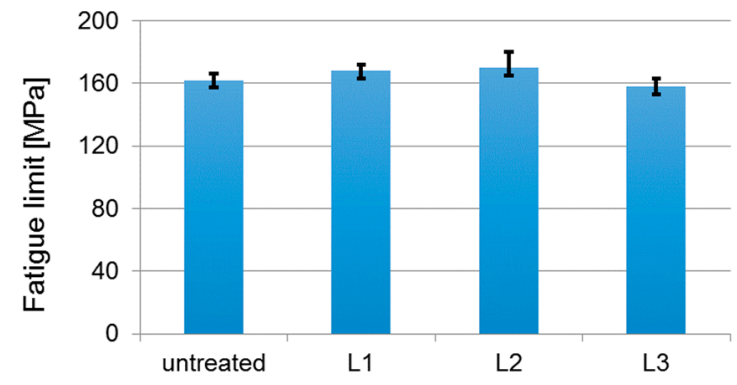

(a) $36 \mathrm{NiCrMo}$

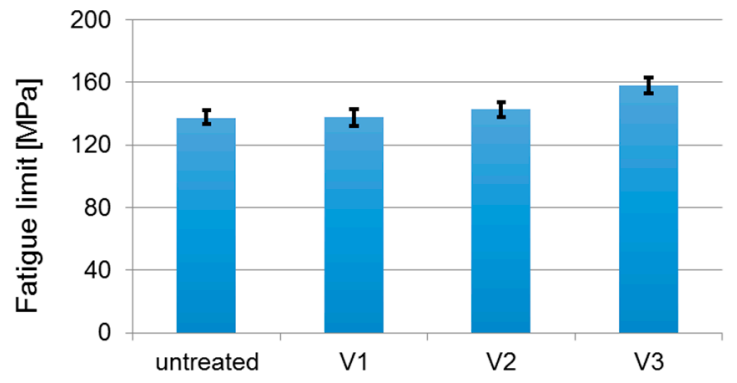

(b) $42 \mathrm{CrMoV}$

Figure 2. Effect of the rolling load level on the fatigue limit (reported in terms of stress amplitude) for the two investigated materials.

For the $36 \mathrm{NiCrMo}$ material, an increasing trend of the fatigue limit can be appreciated moving from the untreated condition to the application of a deep rolling level L2, even if the rise is not so marked (around 5\%). A higher rolling force (L3) led to a fatigue limit drop, which suggests that the optimal load has been exceeded. Regarding the $42 \mathrm{CrMoV}$ material, a greater sensitivity to the deep rolling process can be highlighted: for this material, the fatigue limit is incremented up to $15 \%$, if compared to the as-turned (untreated) condition, following the treatment with V3 level of rolling load. For the aim of the present work, no further rolling load levels have been tested due to the reduced amount of screws of the same batch being available for the project. The optimal rolling load levels L2 and $\mathrm{V} 3$ for the $36 \mathrm{NiCrMo}$ and $42 \mathrm{CrMoV}$ materials, respectively, were therefore assumed for the further design of the experiments. 


\section{Results and Discussion of the Initial Campaign}

The results in terms of the fatigue limits for the two screw materials, $36 \mathrm{NiCrMo}$ and $42 \mathrm{CrMoV}$, are collected in the bar graph in Figure 3, where the letters in the horizontal axis correspond to the treatment combinations in Table 1. Confidence bands at the $95.5 \%$ confidence level are also included.

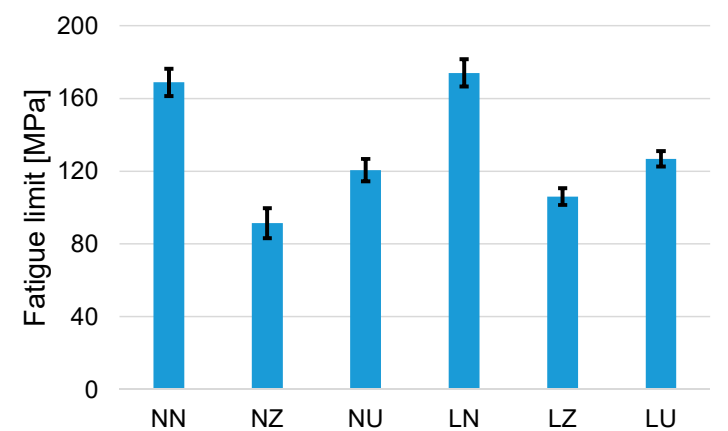

(a) $36 \mathrm{NiCrMo}$

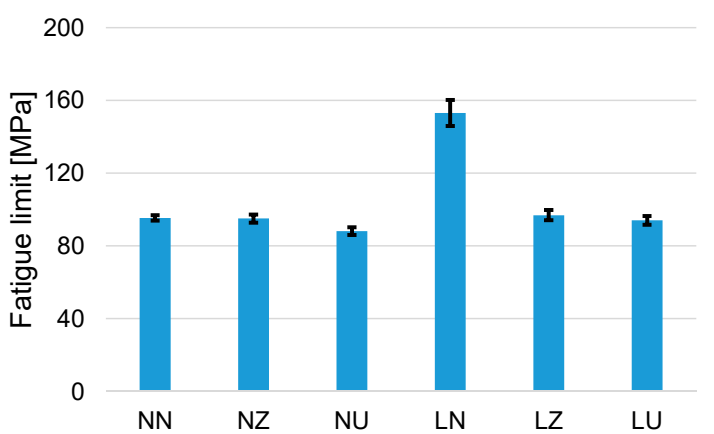

(b) $42 \mathrm{CrMoV}$

Figure 3. Fatigue limits (in terms of stress amplitude) for the treatment combinations of Table 1.

The outcomes of the experimental trials highlight that deep rolling that was performed at the fillet has generally a beneficial impact on fatigue, with specific reference to the failure mode of cracks starting from the fillet. Conversely, shot-peening generally leads to a worsening of the fatigue limit. All of the observed failures consistently initiated from the underhead fillet. The significance of the effects of the two factors was also assessed by the tools of marginal mean plots and of two-factor ANOVA (Analysis of Variance) without replications.

The plots are shown in Figure 4 for the $36 \mathrm{NiCrMo}$ and $42 \mathrm{CrMoV}$ and they well highlight the effects of deep rolling with and without shot peening and of shot-peening with different parameters, involving not rolled or rolled screws.

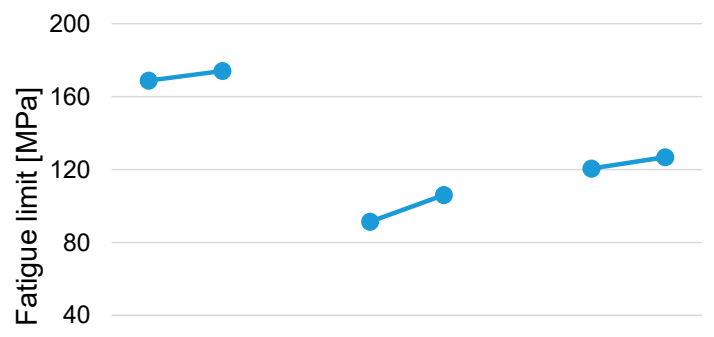

(a) 0

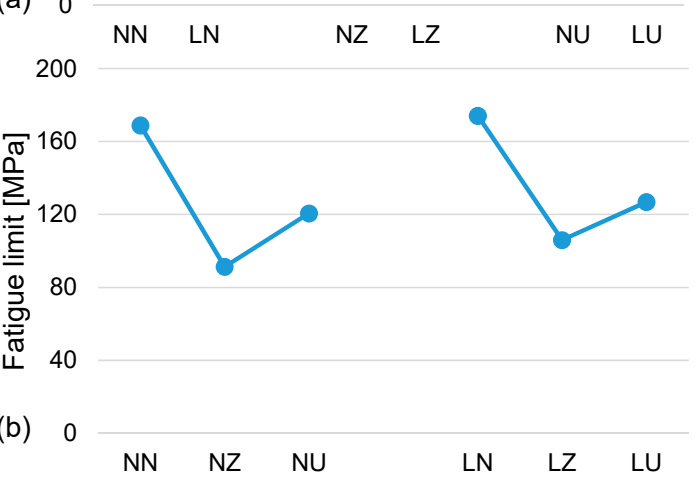

(a) $36 \mathrm{NiCrMo}$

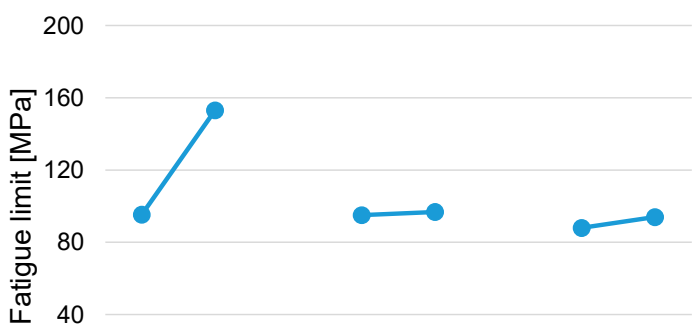

(a) 0
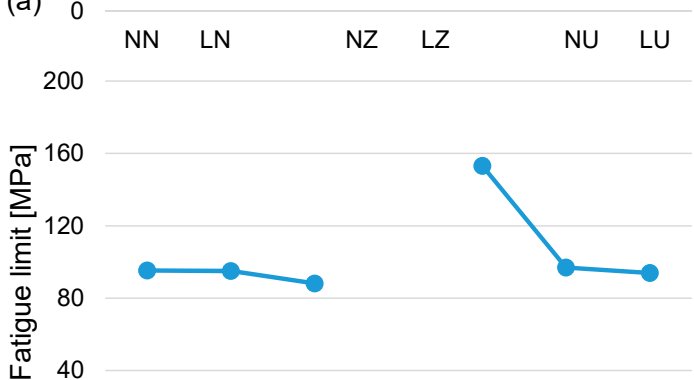

(b)

(b) $42 \mathrm{CrMoV}$

Figure 4. Marginal mean plots: effects of (a) deep rolling and (b) shot-peening (treatment combinations of Table 1 for both materials). 
The results in the terms of the fatigue limits have been processed the ANOVA tool without replications. The outcome of the analysis indicates that the fatigue strength drop due to shot-peening is significant for the first material (36NiCrMo), whereas it keeps below the significance threshold for the second one $(42 \mathrm{CrMoV})$.

The global effect of deep rolling is also not significant, due to the general worsening of performance when shot-peening is applied. However, it should be argued that the aforementioned ANOVA tool can only be applied to experimental scenarios where interactions are not present or negligible. On the opposite, in the present case, huge interactions seem to be present, as the effect of deep rolling is remarkably different, depending on the execution of the subsequent peening treatments. In particular, deep rolling is highly beneficial when shot-peening is not run, whereas it tends to be shadowed when this treatment is performed. This shadowing effect highlights a negative connotation for interaction, which makes it difficult to achieve parameter optimization. Similar considerations also applied to the effect of shot-peening with and without deep rolling.

The presence of interaction indicates that the outcomes of the aforementioned ANOVA are not completely reliable: they may reasonably be used for data analysis at a first glance only, highlighting the presence of interaction at the same time. The analysis has been moved from statistics to microscope observations in order to overcome this issue. In particular, the fatigue results and the detrimental effect of shot-peening have been then addressed in the light of some observations of the treated surface at the shank. Roughness (Ra) measurements have also been run. Observations were performed by a stereo-microscope (Stemi 305; ZEISS, Oberkochen, Germany) with subsequent surface morphology acquisition. On the other hand, roughness measurements by a roughness tester (INTER.RT25P; Alpa, Pontoglio, Brescia, Italy) made it possible to compare the Ra values in the cases of turned and of peened surfaces. Following calibration, the captured microscope images have also been post-processed to estimate the size of the dimples that were generated by the two different peening treatments. Some examples of surfaces are shown in Figure 5 with regard to the combinations "NN" (untreated), "NZ" (Z100), and "NU" (UFS70) of the second material. A few details of the measured dimples for "NZ" and "NU" treatments, respectively, are provided in Figure 6. It can be observed that both the surfaces appear to be significantly pitted, as a result of the $200 \%$ coverage. Image post-processing indicates that the dimple average diametral size is $85 \mu \mathrm{m}$ for NZ and $60 \mu \mathrm{m}$ for NU. When considering that the dimple width is proportionally related to the size of the impacting shots [30], the morphology of these dimples indicates the deep and remarkably strong impact of a large amount of particularly small sized shots, especially for the UFS70 treatment.

The related roughness measurements indicate that the Z100 treatment leads to a roughness increase of up to $1.5 \mu \mathrm{m}$, whereas the UFS70 yields an even higher roughness in the order of $2 \mu \mathrm{m}$. These values must be compared to the roughness of the as-turned unpeened condition, which is just $0.4 \mu \mathrm{m}$. These outcomes, along with the aforementioned dimple size estimation, suggest a significant pitting by a high number of shots: their reduced size implies a huge load concentration at every impact. Thus, the sharp dimples that are created at every impact act as crack triggers that promote crack initiation at the notch root, i.e. at the underhead fillet. This mechanism is increasingly supported by a highly notch sensitive material, while considering the 14.9 resistance grade of the screws. Therefore, these results suggested rearranging the campaign with particular reference to shot-peening parameters, namely the shot diameter and its intensity. The revised campaign, with the aim of achieving a more convenient load distribution upon impacts and a lower and more feasible roughness, is addressed in the section below. 

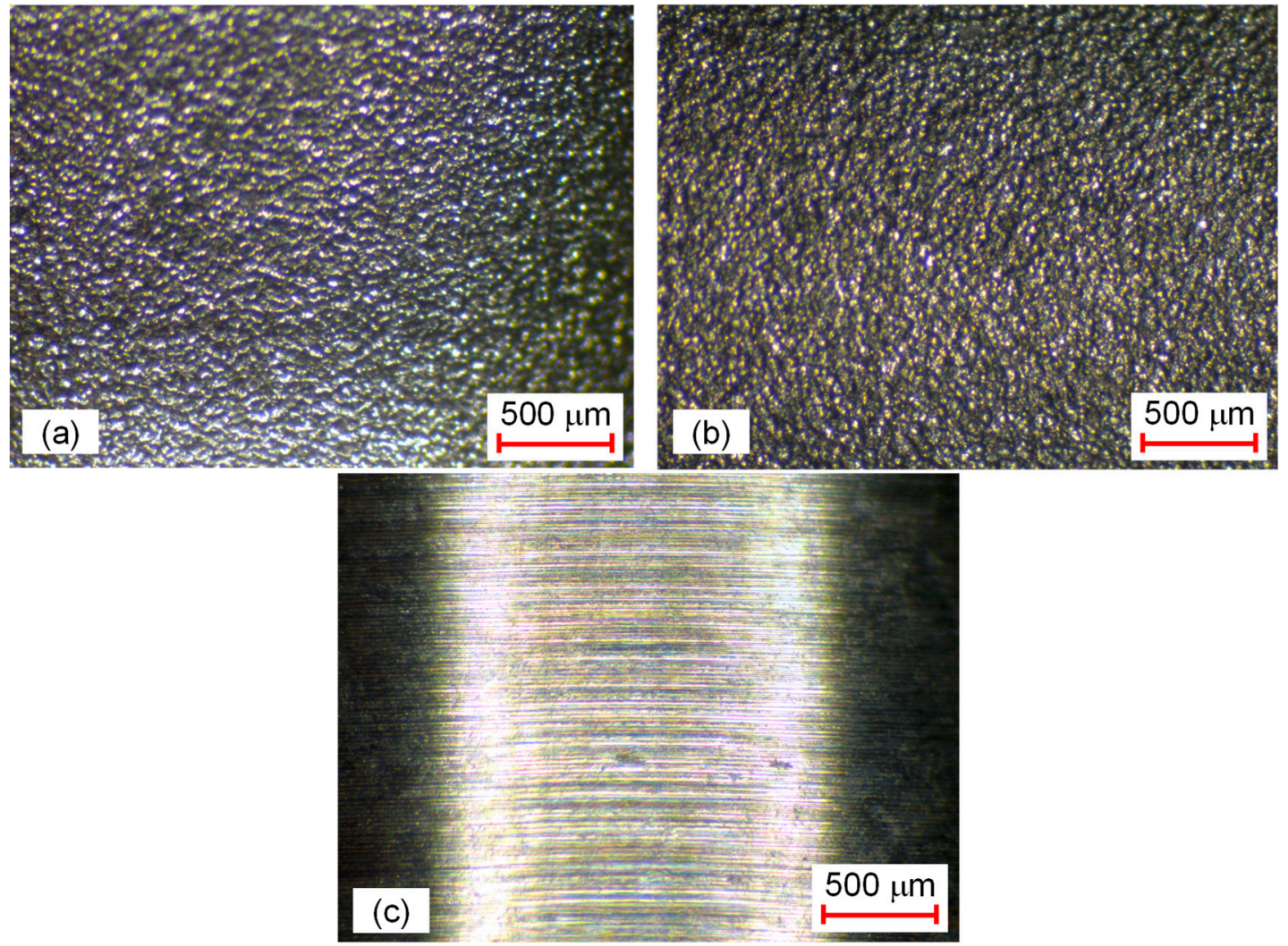

Figure 5. Stereoscopic microscope surface analysis with reference to $42 \mathrm{CrMoV}$ screws treated by (a) Z100 10-12N peening, (b) UFS70 10-12N peening, and (c) just turned the shank.

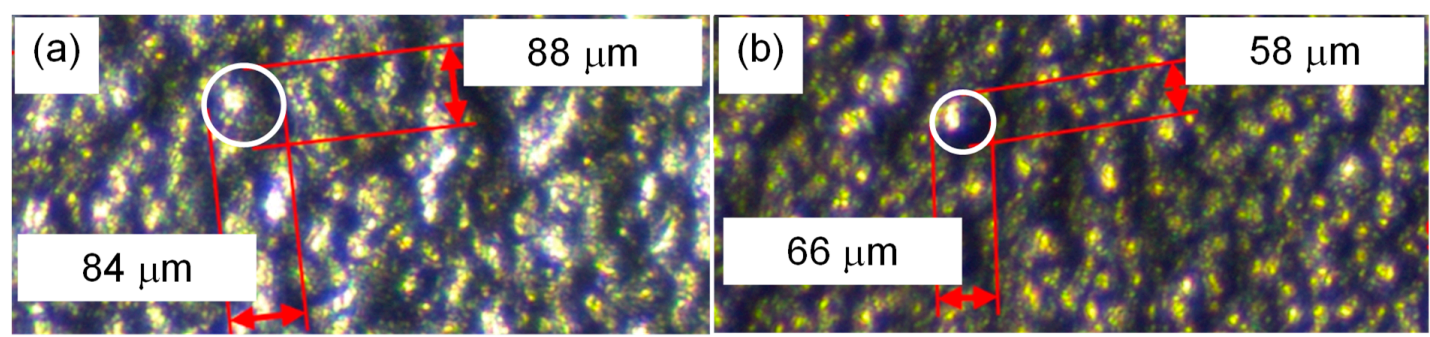

Figure 6. Enlarged detail (stereoscopic microscope observation of $42 \mathrm{CrMoV}$ screws) of the dimples induced by (a) Z100 10-12N; (b) UFS70 10-12N.

\section{Discussion and Design of a Second Campaign}

Previous studies [30-34] indicate that residual stress trends usually exhibit a sub-surface peak. For the shot-peening, the higher the shot diameter, the deeper the subsurface peak. This outcome indicates that, by increasing shot diameter, a lower impact load at the superficial layer can be achieved. From the physical point of view, shots with a greater diameter are able to distribute the transmitted impact load over a greater impact area. The Almen intensity is directly related to the generated compressive residual stress trend and, in particular, to the amount of maximum compressive stress beneath the surface. Therefore, the lower Almen intensity, the lower the induced plastic deformation and, consequently, the severity of the impacts. The achievable roughness is in turn related to the intensity of the impacts and to the surface coverage, although the latter is usually kept at a value higher than $100 \%$ ( $200 \%$ in the present case) to ensure full surface coverage.

Based on the considerations above, the shot-peening parameters were revised, following these two guidelines: (i) considering again peening treatments by ceramic and steel shots but, if possible, with larger sizes than in the previous campaign; (ii) calibrating the Almen intensity in order to achieve 
a Ra roughness not exceeding $1 \mu \mathrm{m}$. In particular, this value was thought to be well compatible with a good fatigue response, while considering the recommendations and remarks in [11,25] and other studies regarding peened parts. In addition, the second campaign was only focused on the set of screws MJ10 X $14 \mathrm{~g}$ grade 14.9 made of $42 \mathrm{CrMoV}$ due to their greater sensitivity to superficial treatments.

As for the ceramic shots, the same Z100 (100 $\mu \mathrm{m}$ diameter) was kept unchanged, as larger diameters for shots of this material are rarely used. However, the Almen intensity was significantly lowered from $10-12 \mathrm{~N}$ to $4 \mathrm{~N}$, in order to meet the roughness specification. With regard to the steel shots, S110 size, corresponding to $280 \mu \mathrm{m}$ diameter, was selected. This diameter is significantly greater than that for UFS70, which was just $70 \mu \mathrm{m}$. In addition, the Almen intensity was also remarkably decreased to 8.8 , thus accomplishing the target roughness. This roughness was later checked to assess the actual fulfilment of the desired value. Table 2 summarizes the experimental design, where, for the sake of readability, suitable acronyms are used to easily and univocally identify the treatments, while also taking their order into account. Like for the previous campaign, the shot-peening treatments, with $200 \%$ coverage, were combined to deep rolling to be performed at the underhead fillet under the optimized load. The two treatments, when planned together, were run according to the following sequence: (i) Shot-peening including the underhead, the unthreaded shank, and the fillet; (ii) deep rolling with equally-spaced rollers acting on the underhead fillet. It needs to be emphasized that the order of shot-peening and deep rolling was swapped with respect to the previous campaign. The base level (NN) and the level corresponding to deep rolling without shot-peening (here referenced as NL, previously indicated as LN) were the same as for the initial campaign. However, further tests were replicated when considering that the execution of a second set of tests had not been initially planned, and therefore no further screws of the same batch had been initially set aside, forcing using screws from a different batch. Consequently, all of the tests of the second campaign were run on screws from a new batch, and the tests in the NN and NL conditions were replicated for consistency reasons. This also makes the comparisons between the results of the two campaigns not meaningful.

Table 2. Two-factor experimental design (second campaign).

\begin{tabular}{lccc}
\hline \multirow{2}{*}{ Deep Rolling } & \multicolumn{3}{c}{ Shot-Peening } \\
\cline { 2 - 4 } & Not Performed & Z100 4N & S110 8.8N \\
\hline Not Performed & NN & ZN & SN \\
Performed at the & NL & ZL & SL \\
Optimized Load & & & \\
\hline
\end{tabular}

The fatigue tests were performed on the same resonant machine under a tension-tension load with a fixed mean value again corresponding to screw recommended preload (around $85 \%$ of the yield strength). The load ratio (minimum over maximum ratio) was around 0.8 for all of the experimental trials.

As for the previous campaign, the fatigue tests were aimed at the determination of the fatigue limit for infinite life. For this purpose, the same two million cycles run-out was selected and the Dixon method [27] for abbreviated staircase was adopted. A confidence analysis was performed as well, while considering a 90\% confidence level. In addition, S-N curves were determined, following the recommendations of ISO 12107 [26]. When considering the applied tension-tension cycle, stress amplitude was plotted against life cycles in a Log-Log diagram. Based on the recommendations by the Standard, the general linear test was applied to assess whether the improvement yielded by the quadratic model was significant, if compared to the linear interpolation. The confidence band for a $10-90 \%$ probability of failure and a $90 \%$ confidence level was also determined and wrapped around the nominal curve for $50 \%$ failure probability. A statistical approach that was based on a generalized ANOVA for the comparison of trends, first introduced in [35] and successfully applied in [36], was also adopted to compare the fatigue strengths to the scattering of the results. As already highlighted, results were discussed within the tests that were performed in this second experimental campaign, without 
making comparisons with the outcomes of the previous one, due to the different material batch of the screws.

\section{Results and Discussion of the Second Campaign}

Figure 7 provides the outcomes of the experimental campaign. In particular, the bar graph shows the fatigue limits for $42 \mathrm{CrMoV}$ screws under the six treatment combinations of Table 2 . Confidence bands are also appended to each result, while considering a 90\% confidence level and accounting for the standard deviation affecting the limit, being related to data scattering, and for the number of trials at staircase. Regarding this point, the fatigue limits have been worked out, processing sequences consisting of seven to 10 nominal tests, in the typical range of the Dixon method.

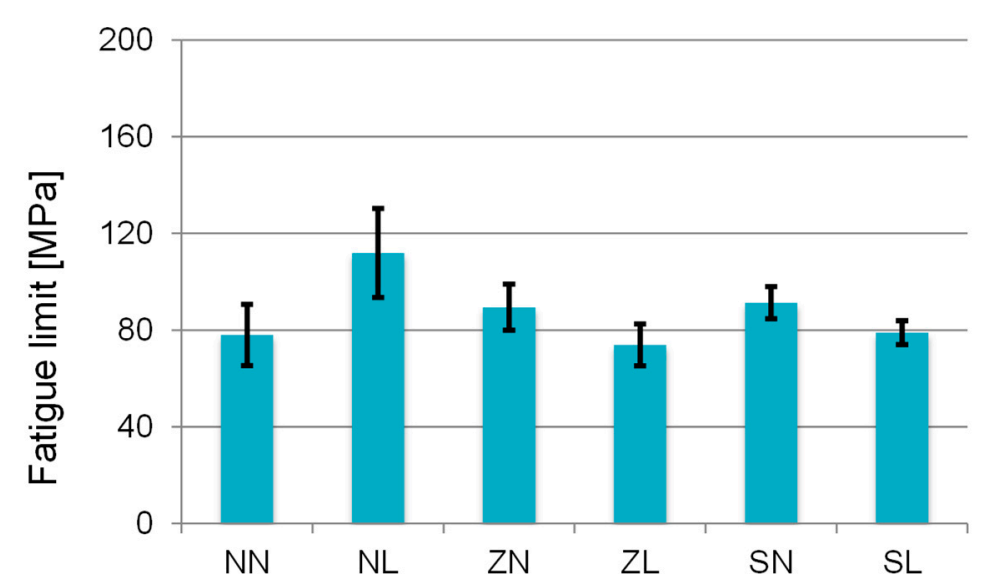

Figure 7. Fatigue limits (in terms of stress amplitude) for the treatment combinations of Table 2, with regard to the second fatigue campaign $(42 \mathrm{CrMoV})$.

The results confirm that deep rolling significantly affects the fatigue strength: it has a beneficial impact and leads to a $43 \%$ fatigue limit increment with respect to the untreated conditions. On the other hand, it is worth mentioning that, following parameter revision, shot-peening also turns to be beneficial: in fact, the $\mathrm{Z} 100-4 \mathrm{~N}$ treatment led to an increment in the order of $15 \%$ with respect to the untreated conditions. Moreover, S110-8.8N peening led to a slightly higher increment up to $17 \%$. However, the remarked fatigue enhancements keep lower than the achievable improvement by deep rolling at underhead fillets. The latter, which strengthens the screw at its weakest point, while considering the usual failure mode for connecting rod fasteners, proved to be the most effective. Skipping then to the combined effect of shot-peening and deep rolling, a moderate negative interaction, like for the previous campaign, can be observed again. The tool of marginal mean plots has been utilized in order to better address the effects of the two investigated factors along with their interaction. These plots, depicted in Figure 8, confirm that deep rolling and shot-peening, taken alone, are both beneficial, but the first one implies a steeper fatigue limit increment.

On the other hand, when shot-peening is followed by deep rolling, the fatigue strength is lowered and the results are made comparable to those of the as-turned screw. This outcome again indicates that shot-peening, often regarded as a highly beneficial surface treatment to prevent fatigue failures, might have a controversial effect, when applied in the neighbourhood of very sharp notches (like the underhead fillet) and to highly notch sensitive materials, in combination with a further strong plastic treatment. Regarding this points, it is worth mentioning that the investigated screws have 14.9 resistance grade, which makes notch sensitivity drastically increase, as it is, in turn, proportional to the material ultimate tensile strength. 


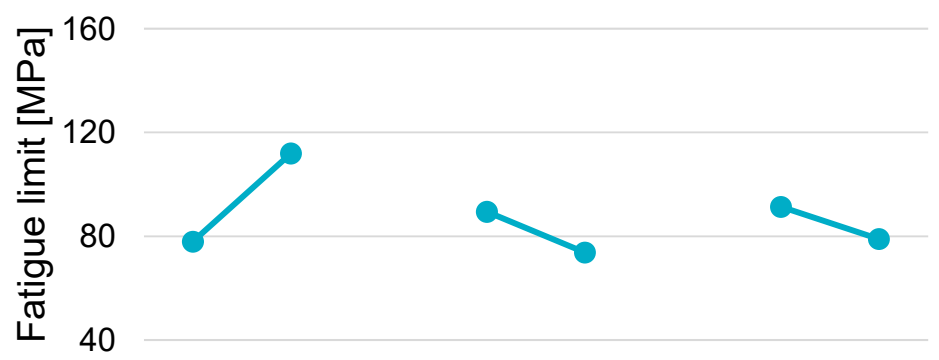

(a)

$\begin{array}{rrrrrrrr}0 & \mathrm{NN} & \mathrm{NL} & \mathrm{ZN} & \mathrm{ZL} & \mathrm{SN} & \mathrm{SL} \\ 200 & & & \end{array}$

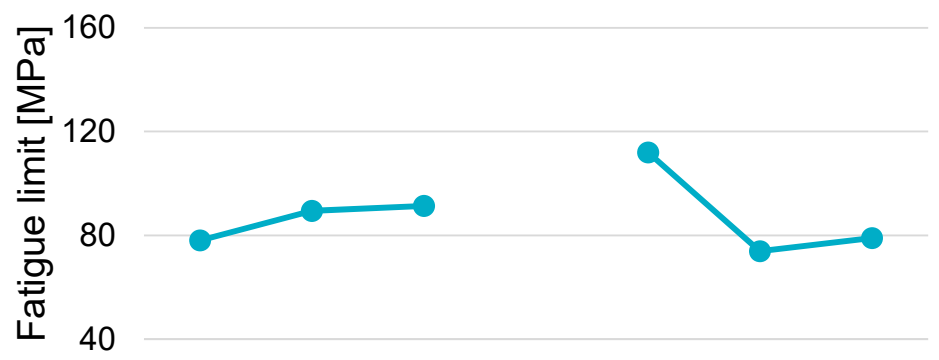

(b)

0

NN $\quad$ ZN $\quad$ SN $\quad$ NL $\quad$ ZL $\quad$ SL

Figure 8. Marginal mean plots dealing with the effects of (a) deep rolling and (b) shot-peening (treatment combinations of Table 2, with regard to the second fatigue campaign).

A further possible source for this outcome could be related to some slight deviations of the rolls from their path operating at the fillet upon deep rolling, due to some surface irregularities, namely the dimples, which are induced by shot-peening. These deviations are likely to induce some marks that might trigger microcracks and then failure (Figure 9).
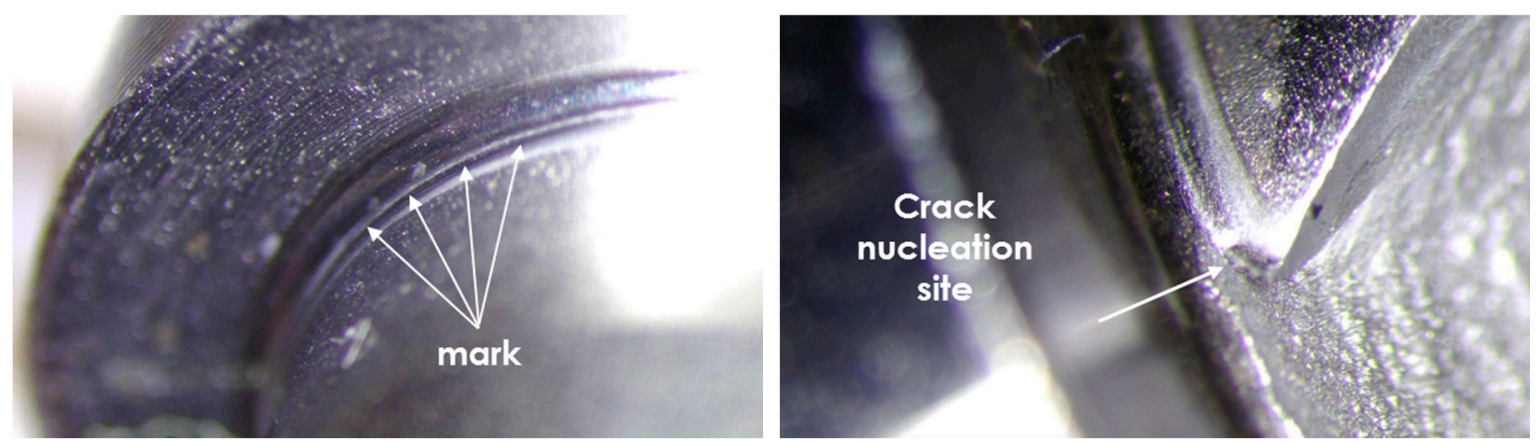

Figure 9. (left) The mark left by the rolls after shot-peening and (right) a failed screw with evidence of the crack nucleation site at the mark.

The aforementioned remarks, dealing with fatigue in the infinite life domain, are confirmed by the fatigue responses for finite life. As a first remark, the improvement yielded by the quadratic model always proved to be not significant, so that the linear model was regarded as the most suitable. The S-N curves for the NN, NL, ZN, and ZL treatments are plotted together in Figure 10; run-out 
events, with several overlapped points, are also present and highlighted by arrows. The curves for $\mathrm{SN}$ and SL combinations are omitted here for the sake of synthesis, when considering that the fatigue strengths of the two peening treatments, with and without deep rolling, are well aligned.

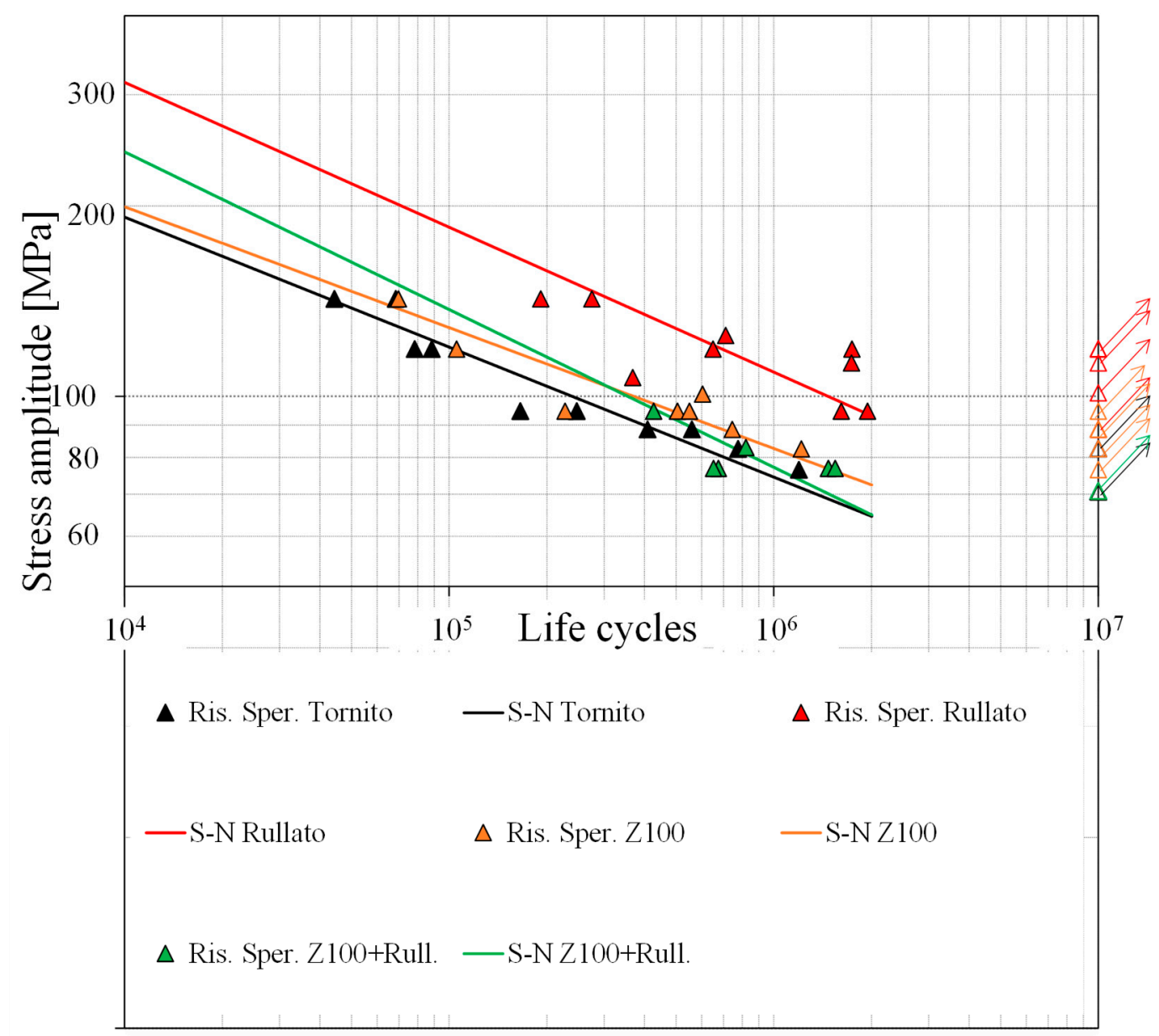

Figure 10. S-N curves in the finite life domain plotted together for the NN, NL, ZN, and ZL treatments of the second fatigue campaign.

The curves for the four treatments are also plotted together with their confidence bands in Figure 11. The curves have been compared by the statistical test described in $[35,36]$ for the comparison of fatigue trends. The results, which were processed by the tools of ANOVA and Fisher test, indicate that deep rolling keeps a significant beneficial impact in the finite life domain, whereas the effect of shot-peening is under the significance threshold. The analysis also highlights a moderate interaction between these two factors that is significant at the $8 \%$ threshold.

The combined shot-peening plus deep rolling treatment looks attractive, as, on one hand, deep rolling proved to be highly beneficial for fatigue, on the other hand some studies [21,22] indicate that shot-peening is able to remarkably enhance the tribological properties of the screw at its underhead. In particular, it can be used to reduce the frictional coefficient and to make it steady, even following repeated tightenings. The highlighted drawback that is related to the negative interaction between these two factors could be reasonably reduced by better calibrating the load transmitted by the rollers upon deep rolling. 

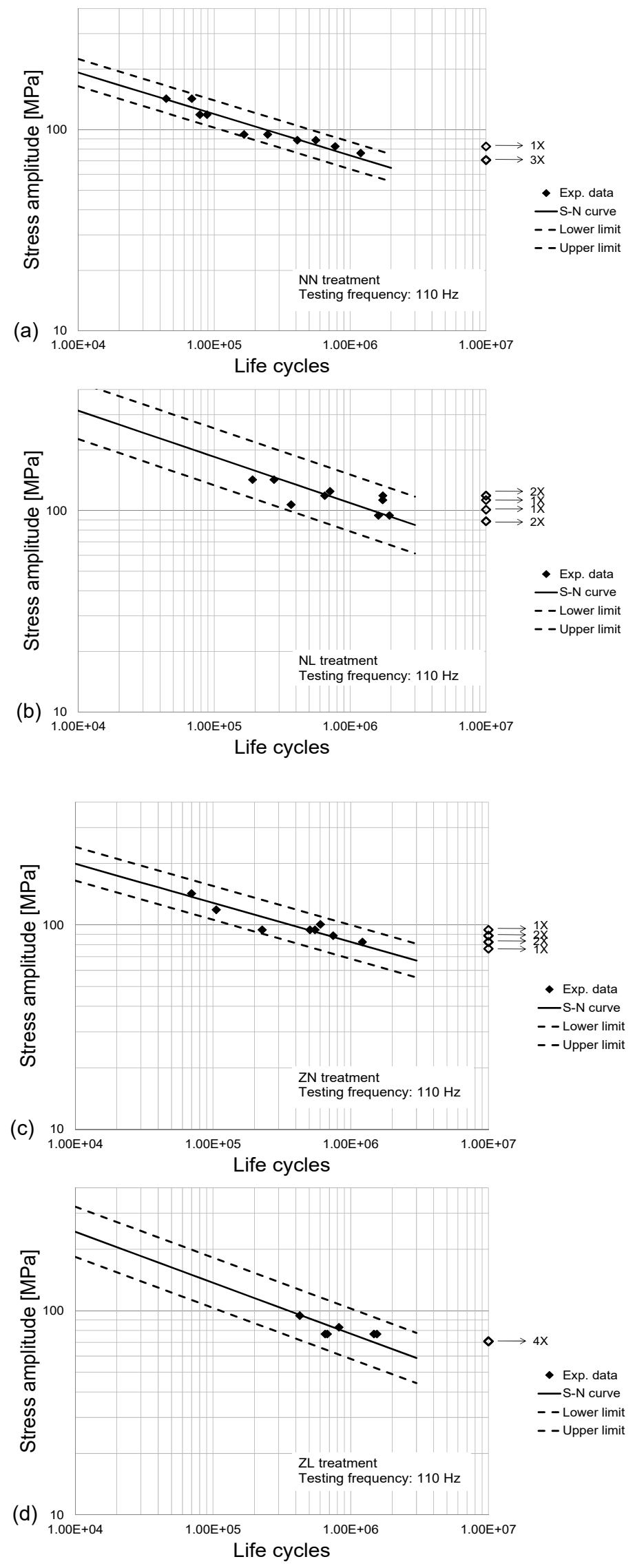

Figure 11. S-N curves in the finite life domain sketched along with their confidence bands for (a) NN, (b) NL, (c) ZN and (d) ZL treatments of the second fatigue campaign. 
For combined treatment, such a load should be reasonably reduced in order to account for the previous shot-peening, which results in a pre-existing plastic deformation. As previously reported, literature studies [2] have indicated that, if the optimal load for deep rolling is exceeded, it may result in a highly detrimental effect from the point of view of fatigue strength. In addition, the roller path at the fillet, under a lower load transmitted at the contact, would be presumably less affected by the presence of dimples.

\section{Conclusions}

In the present work, two sets of fasteners made of high strength steels have been experimentally tested under various combinations of deep rolling and shot-peening surface treatments performed at the underhead fillet radius to assess their impact on the fatigue resistance. Two experimental campaigns have been carried out, with different sets of treatment parameters and sequence. The main outcomes of the work can be summarized, as follows:

1. An always-beneficial impact of deep rolling on fatigue was found, especially for the investigated $42 \mathrm{CrMoV}$ steel that showed an increment of $43 \%$ with respect to the untreated (as-turned) condition, following rolling load optimization.

2. In the investigated range of rolling loads, the existence of an optimal value has been clearly proved for the $36 \mathrm{NiCrMo}$ material, for which a further increase led to a fatigue limit drop, confirming what reported in literature.

3. The outcomes of the shot-peening (performed alone) strongly depended on the selected set of process parameters. With the Z100-4N and S110-8.8N treatments (high shots diameters and low Almen intensity), increments of $15 \%$ and $17 \%$ respectively versus the as-turned condition for the $42 \mathrm{CrMoV}$ were observed.

4. When shot-peening was combined to and performed after the deep rolling, the fatigue limit decreased if compared to both the deep rolled state (at optimal load) and the untreated condition, especially for the $36 \mathrm{NiCrMo}$ material. This was attributed to the increment of the surface roughness that was induced by the process with the selected initial set of parameters, also in consideration of the here investigated highly notch sensitive materials.

5. When shot-peening was followed by deep rolling, the fatigue strength was lower than that of the deep rolled condition (at optimal load) and it was made comparable to those of the as-turned screws. This outcome indicated that shot-peening may have a controversial effect, when applied in the neighbourhood of very sharp notches (like the underhead fillet) and to highly notch sensitive materials.

Author Contributions: Conceptualization, B.R. and G.O.; data curation, B.R.; Formal analysis, G.O.; Investigation, B.R.and G.O.; Methodology, B.R. and G.O.

Funding: This research activity was founded by VIMI Fasteners, Novellara (RE), in the framework of a commercial research contract.

Acknowledgments: The authors would like to thank VIMI Fasteners, Novellara (RE), Italy for the manufacturing of the fasteners and the key support throughout the overall project. In particular, a great thank goes to Lorenzo Barozzi for having performed the fatigue and deep rolling tests. Thanks also to Michele Bandini of the Peen Service, Bologna, Italy, for the shot-peening treatments.

Conflicts of Interest: The authors declare no conflict of interest.

\section{References}

1. Bhuvaraghan, B.; Prakash, O.; Sivakumar, M.S.; Potdar, Y.; Maffeo, B.; Doma, P. Overview of the effects of surface enhancement processes on plastic strain, work hardening and residual stresses. In Proceedings of the International Conferences on Shot Peening ICSP-6, San Francisco, CA, USA, 2-5 September 1996.

2. Altenberger, I. Deep rolling-The past, the present and the future. In Proceedings of the International Conferences on Shot Peening ICSP-9, Paris, France, 6-9 September 2005; Volume 144. 
3. Totten, G.; Howes, M.; Inoue, T. Handbook of Residual Stress and Deformation of Steel; ASM International: Materials Park, OH, USA, 2003.

4. Wierzchowski, D.; Ostertag, A.; Wagner, L. Fatigue Performance of the Mechanically Surface Treated Steels 42CrMo4 and 54SiCr6: Shot Peening vs. Roller-Burnishing. In Proceedings of the International Conferences on Shot Peening ICSP-8, Garmisch-Partenkirchen, Germany, 16-20 September 2002; pp. 468-473.

5. Altenberger, I. Alternative Mechanical Surface Treatments: Microstructures, Residual Stresses \& Fatigue Behavior. In Proceedings of the International Conferences on Shot Peening ICSP-8, Garmisch-Partenkirchen, Germany, 16-20 September 2002; pp. 421-434.

6. Hutchings, F.R.; Unterweiser, P.M. Failure Analysis: The British Engine Technical Reports; American Society for Metals: Materials Park, OH, USA, 1981.

7. O'Brien, M.J.; Metcalfe, R.G. High strength engineering fasteners: Design for fatigue resistance. J. Fail. Anal. Prev. 2009, 9, 171-181. [CrossRef]

8. Fernández-Pariente, L.; Bagherifard, S.; Guagliano, M.; Ghelichi, R. Fatigue behavior of nitrided and shot peened steel with artificial small surface defects. Eng. Fract. Mech. 2013, 103, 2-9. [CrossRef]

9. Olmi, G.; Freddi, A. A new method for modelling the support effect under rotating bending fatigue: Application to Ti-6Al-4V alloy, with and without shot peening. Fatigue Fract. Eng. Mater. Struct. 2013, 36, 981-993. [CrossRef]

10. Altenberger, I.; Scholtes, B.; Martin, U.; Oettel, H. Cyclic deformation and near surface microstructures of shot peened or deep rolled austenitic stainless steel AISI 304. Mater. Sci. Eng. 1999, 264, 1-16. [CrossRef]

11. Croccolo, D.; De Agostinis, M.; Fini, S.; Olmi, G.; Robusto, F.; Ciric-Kostic, S.; Vranic, A.; Bogojevic, N. Fatigue response of as-built DMLS maraging steel and effects of aging, machining, and peening treatments. Metals 2018, 8, 505. [CrossRef]

12. Terres, M.A.; Laalai, N.; Sidhom, H. Effect of nitriding and shot-peening on the fatigue behavior of $42 \mathrm{CrMo} 4$ steel: Experimental analysis and predictive approach. Mater. Des. 2012, 35, 741-748. [CrossRef]

13. Abrão, A.M.; Denkena, B.; Köhler, J.; Breidenstein, B.; Mörke, T.; Rodrigues, P.C.M. The influence of heat treatment and deep rolling on the mechanicalproperties and integrity of AISI 1060 steel. J. Mater. Process. Technol. 2014, 214, 3020-3030. [CrossRef]

14. Çevik, G.; Tuncali, Z.; Duran, E.T. A Study on the Diesel Engine Crankshaft Fatigue Performance Optimization. SAE Int. 2009, 145-157. [CrossRef]

15. Quraishi, I.M.; Harne, M. Fatigue Strength and residual stress analysis of deep rolled crankshafts. Int. J. Eng. Technol. 2012, 4, 466-473.

16. Çevik, G.; Gürbüz, R. Evaluation of fatigue performance of a fillet rolled diesel engine crankshaft. Eng. Fail. Anal. 2013, 27, 250-261. [CrossRef]

17. Spiteri, P.; Ho, S.; Lee, Y.L. Assessment of bending fatigue limit for crankshaft sections with inclusion of residual stresses. Int. J. Fatigue 2007, 29, 318-329. [CrossRef]

18. Li, W.; Zhang, S.Y.; Kabra, S.; Tremsin, A.; Abbey, B.; Kirkwood, H.; Terret, D.; Ndoye, S.; McDevitt, E. Characterisation of Residual Stress due to Fillet Rolling on Bolts Made of a Nickel Base Superalloy. In Proceedings of the 9th European Conference on Residual Stress ECRS-9, Troyes, France, 7-10 July 2014.

19. Bian, J.; Mohrbacher, H.; Zhang, J.S.; Zhao, Y.T.; Lu, H.Z.; Dong, H. Application potential of high performance steels for weight reduction and efficiency increase in commercial vehicles. Adv. Manuf. 2015, 3, 27-36. [CrossRef]

20. Kloss, K.H.; Kaiser, B.; Jung, U. Einflusse der Verfahrensparameter des Festwalzens auf die Schwingfestigkeit bautelahnlicher proben. Konsutruction 1995, 47, 97-101.

21. Mitrovic, S.; Adamovic, D.; Zivic, F.; Dzunic, D.; Pantic, M. Friction and wear behavior of shot peened surfaces of 36CrNiMo4 and 36NiCrMo16 alloyed steels under dry and lubricated contact conditions. Appl. Surf. Sci. 2014, 290, 223-232. [CrossRef]

22. Matsui, M.; Kakishima, H. Improvement of tribological performance of steel by solid lubricant shot-peening in dry rolling/sliding contact wear tests. Wear 2006, 260, 669-673. [CrossRef]

23. Reggiani, B.; Olmi, G. Effects of Surface Treatments on the Fatigue Response of High Strength Fasteners. Key Eng. Mater. 2019, 813, 352-357. [CrossRef]

24. Kedziora, S. Optimal design of cap screw thread runout for transversal and axial loads. J. Appl. Mech. Eng. 2017, 6, 250.

25. Niemann, G.; Winter, H.; Hohn, B.R. Maschinenelemente; Springer: Berlin, Germany, 2005. 
26. ISO 12107. Metallic Materials_Fatigue Testing—Statistical Planning and Analysis of Data; International Organization for Standardization: Geneva, Switzerland, 2012.

27. Dixon, W.J.; Massey, F.J. Introduction to Statistical Analysis; McGraw-Hill: New York, NY, USA, 1983.

28. Lyubenova, N.; Baehre, D. Finite element modelling and investigation of the process parameters in deep rolling of AISI 4140 steel. J. Mater. Sci. Eng. B 2015, 5, 277-287.

29. Manouchehrifar, A.; Alasvand, K. Simulation and Research on Deep Rolling Process Parameters. Int. J. Adv. Des. Manuf. Technol. 2012, 5, 31-37.

30. Seddik, R.; Bahloul, A.; Atig, A.; Fathallah, R. A simple methodology to optimize shot-peening process parameters using finite element simulations. Int. J. Adv. Manuf. Technol. 2017, 90, 2345-2361. [CrossRef]

31. Olmi, G.; Comandini, M.; Freddi, A. Fatigue on shotpeened gears: Experimentation, simulation and sensitivity analyses. Strain 2010, 46, 382-395. [CrossRef]

32. Lundberg, M.; Peng, R.L.; Ahmad, M.; Vuoristo, T.; Bäckström, D.; Johansson, S. Influence of shot peening parameters on residual stresses in flake and vermicular cast irons. Mater. Sci. Forum 2014, 768-769, 534-541. [CrossRef]

33. Lundberg, M.; Peng, R.L.; Ahmad, M.; Vuoristo, T.; Bäckström, D.; Johansson, S. Residual stresses in shot peened Grey and compact iron. HTM J. Heat Treat. Mater. 2014, 69, 38-45. [CrossRef]

34. Asgari, A.; Dehestani, P.; Poruraminaie, I. On the residual stress modeling of shot-peened AISI 4340 steel: Finite element and response surface methods. Mech. Ind. 2017, 18, 605. [CrossRef]

35. Olmi, G. Low cycle fatigue experiments on turbogenerator steels and a new method for defining confidence bands. J. Test. Eval. 2012, 40, 104548. [CrossRef]

36. Croccolo, D.; De Agostinis, M.; Fini, S.; Olmi, G.; Bogojevic, N.; Ciric-Kostic, S. Effects of build orientation and thickness of allowance on the fatigue behaviour of 15-5 PH stainless steel manufactured by DMLS. Fatigue Fract. Eng. Mater. Struct. 2018, 41, 900-916. [CrossRef]

(C) 2019 by the authors. Licensee MDPI, Basel, Switzerland. This article is an open access article distributed under the terms and conditions of the Creative Commons Attribution (CC BY) license (http://creativecommons.org/licenses/by/4.0/). 